Проведение оценки кадровой политики по указанным направлениям позволит определить, каким образом в конкретном муниципальном органе осуществляется кадровая работа, отражающая его кадровую политику.

$$
* * *
$$

1. Меньшова В. Н., Ступак И. М. Кадровая работа в сфере государственного и муниципального управления: зоны риска // СИСП. 2011. №3. [Электронный ресурс] / URL: https://cyberleninka.ru/article/n/kadrovayarabota-v-sfere-gosudarstvennogo-i-munitsipalnogoupravleniya-zony-riska (дата обращения: 29.10.2018).

2. Богдан Н.Н. Кадровая работа в муниципальной службе. Новосибирск, СИУ. 2011. 282 с.

3. Жук И.А., Трифонов Ю.Н. Организация кадровой работы на муниципальной службе и пути ее совершенствования // Ученые записки Тамбовского отделения РоСМУ. 2017. №8. [Электронный pecypc] / URL: https://cyberleninka.ru (дата обращения: 04.01.2019).

4. Еремин С.Г. О задачах и организации работы кадровой службы в муниципальном образовании//Актуальные вопросы науки. 2018. №36. С.6567.

5. Дудяшова В.П. Выработка кадровой политики в условиях самообучающейся организации: статья / В.П. Дудяшова, М.А. Снурницина // Актуальные направления научных исследований: от теории к практике. Чебоксары: Интерактив плюс. - 2015. - №1. С. 306-309.

\title{
Юшаева Р.С.-Э. ${ }^{2}$, Яндарбаева Л.А. ${ }^{1}$, Дикаева Х.М. ${ }^{1}$ Развитие предпринимательства в современной России
}

${ }^{1}$ ФББОУ ВО «Чеченский государственный университет»

${ }^{2}$ ФГБОУ ВО «Чеченский государственный педагогический университет»

(Россия, Грозный)

doi: 10.18411/lj-11-2019-134

idsp: ljournal-11-2019-134

\section{Аннотация}

В статье авторами рассматривается развития предпринимательства на современном этапе хозяйствования, на его основе выявлены основные факторы мотивации для предпринимательства, а также определены перспективы в части развития направлений совершенствования малого и среднего предпринимательства.

Ключевые слова: предпринимательская прибыль, предпринимательская деятельность, национальный доход, экономическая и социальная политика.

\section{Abstract}

In the article, the authors consider the development of entrepreneurship at the current stage of management, on its basis the main factors of motivation for entrepreneurship are identified, and prospects for the development of areas for improving small and medium-sized enterprises are identified.

Key words: entrepreneurial profit, entrepreneurial activity, national income, economic and social policy.

Предпринимательская прибыль - это особый доход, вознаграждение предприятий, специфическая творческая деятельность в сфере частных предприятий, воплощенная в новых идеях, технологиях и организационных инновациях для достижения коммерческого успеха.

Конечно, основной мотивацией для предпринимательства является прибыль доход, остающийся после вычета расходов работника и вознаграждений из выручки, является собственностью предпринимателя и может быть оставлен на его усмотрение.

Погоня за прибылью позволяет предпринимателям рисковать капиталом, нанимать работников и покупать все, что им нужнодля эффективного ведения бизнеса. Прибыль также является движущей силой повышения качества продукта или услуги, снижения затрат и продаж по сравнению с конкурентами. 
Однако зарабатывание денег - не единственная причина мотивировать людей заниматься бизнесом. Мотивацией начать собственный бизнес также может быть стремление к индивидуальной независимости, умение выполнять любую работу в удобное время, умение демонстрировать свои способности или продолжать семейные традиции.

Независимо от успеха бизнеса родителей, выходцы из коммерческих домохозяйств, как правило, начинают свой собственный бизнес в большей степени, чем другие. Видимо, родственники, которые занимаются предпринимательской деятельностью и поощряются плодами своей работы, иллюстрируют примеры возможного выбора профессии.

Независимо от мотивации и масштабов деятельности предприниматели достигают своих способностей, выполняя следующие функции: общая экономика, творческий поиск, ресурсы, общество, организация. Чем эффективнее работает предпринимательская организация, тем выше ее доход на всех уровнях бюджета и национального внебюджетного социального фонда. В то же время развитие предпринимательства привело к увеличению числа занятых, снижению уровня безработицы и улучшению социального статуса работников.

Важнейшей функцией предпринимательства является организаторская, которая проявляется в том, что предприниматели ведут свой бизнес, диверсифицируют, внедряют предпринимательство на предприятии, формируют управление предприятием, создают сложные предпринимательские структуры, меняют бизнесстратегию начинающих компаний и самостоятельное принятие решений. Организационная функция ярко выражена в создании массовых предприятий[1].

Дефицит долгосрочных кредитных ресурсов на рынке кредитования малого бизнеса продолжает оставаться одним из важнейших факторов, сдерживающих экономическое развитие.

Увеличение сроков кредитования происходит за счет готовности некоторых банков кредитовать малый бизнес на большие суммы и на более долгие сроки, и на фоне роста спроса на инвестиционные кредиты со стороны малого предпринимательства.

Конкретно для производственного предпринимательства характерна еще одна проблема. В Чеченской республике недостаточно развита производственная инфраструктура поддержки малого предпринимательства.

Обеспеченность объектами производственной инфраструктуры остается крайне низкой. В крае почти не производятся товары легкой промышленности и многие продукты питания, а если и производятся, то в недостаточном количестве. Проще и дешевле доставить продукт, чем производить эту продукцию. Негативное воздействие на развитие малого бизнеса в сфере производства оказывают также нехватка специализированного оборудования, слабость информационной базы.

Анализ состояния малого предпринимательства в республики обозначил основные проблемы, сдерживающие развитие малого бизнеса:

- нехватка собственных оборотных средств;

- ограниченный доступ к кредитным ресурсам (в основном из-за недостаточности ликвидного, имущественного обеспечения);

- постоянный рост цен на энергоносители и сырье;

- высокие ставки арендной платы на рынке коммерческой недвижимости;

- усиливающаяся конкуренция со стороны крупных сетевых компаний федерального уровня.

Так как существует много препятствий на пути создания массовых малых предприятий в данном случае предложить основные критерии по решению проблем, препятствующих осуществлению функционирования предпринимательства[2]: 
- развитие банковской системы республики;

- снижение необоснованно завышенных ставок арендной платы за коммерческие площади, (уровня арендной платы);

- упрощение процедуры предоставления следующих муниципальных услуг субъектам малого и среднего предпринимательства (nутем перевода в электронный вид):

- услуга выдачи разрешения на строительство объектов капитального строительства;

- услуга перевода жилого помещения в нежилое помещение или нежилого помещения в жилое помещение;

- услуга выдачи разрешений на установку рекламных конструкций на соответствующей территории и согласование размещения информации[3].

На фоне существующей ситуации возникает необходимость открытия собственного коммерческого банка с развитой системой представительств

Достижение прогнозируемых показателей будет обеспечено за счет реализации мер экономической и социальной политики на федеральном и республиканском уровне:

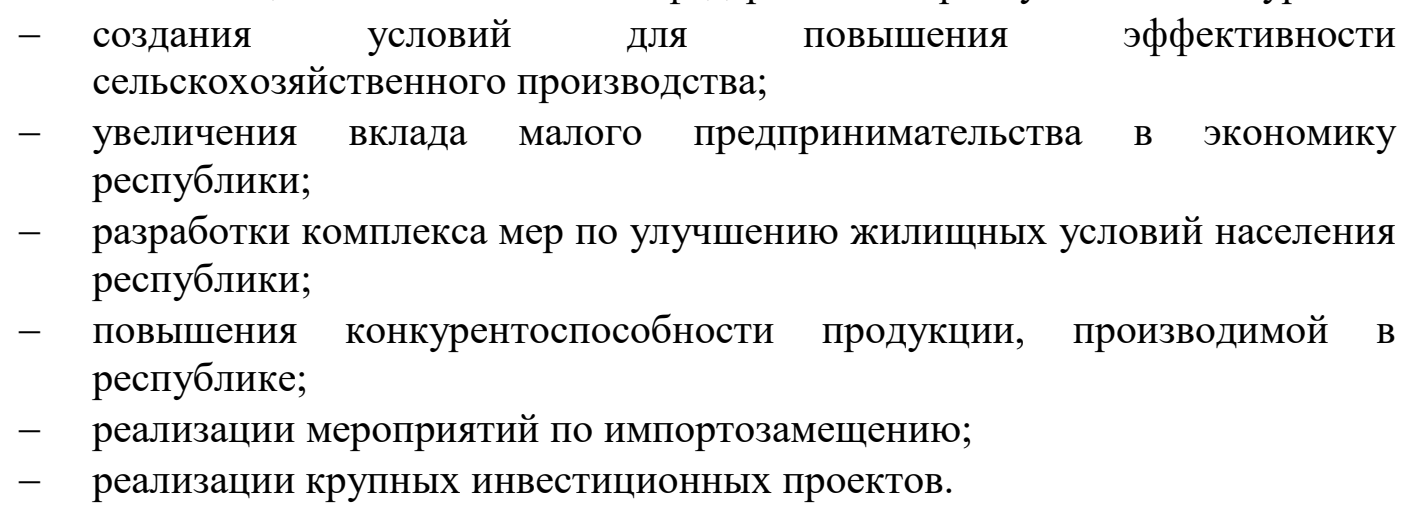

1. Илаева 3.М. Анализ инвестиционного процесса в кризисных ситуациях в регионах на примере ЧР //ФГУ Science. - 2017. - № 1 (9). - С. 78-82.

2. Гайрбекова Р.С. Стратегическое планирование устойчивого развития муниципального образования// ФГУ Science, ФГБОУ ВО «Чеченский государственный университет» № 1 (9) Грозный: Издательство ЧГУ, 2017. - С. 41-44.

3. Довлетмурзаева М.А.Сущность процесса управления персоналом организации на современном этапе//ФГУ Science, ФГБОУ ВО«Чеченский государственный университет» № 1(9) - Грозный: Издательство ЧГУ, 2017. - С. 61-64.

\section{Яндарбаева Л. А., Дикаева Х.М. \\ Стратегическое управление предприятием}

ФГБОУ ВО «Чеченский государственный университет» (Россия, Грозный)

doi: $10.18411 / \mathrm{lj}-11-2019-135$

idsp: ljournal-11-2019-135

\section{Аннотация}

Стратегическое управление неотъемлемая часть работы любого предприятия. Оно ставит перед собой ряд целей и задач в процессе осуществления долгосрочных планов и перспектив. На сегодняшний день одним из наиболее эффективных способов наращивания производства является потенциал предприятия. Авторами рассмотрена актуальность данной темы, негативное влияние финансовых и операционных рисков, дано понятие стратегического потенциала и угроз для предприятия. 